\title{
ANALISIS GAYA BAHASA DAN PERSAJAKAN PADA KUMPULAN LAGU ARMADI RAGA DALAM ALBUM $A U$
}

\author{
Merlita Sari $^{1}$, Siti Rukiyah ${ }^{2}$, Arif Ardiansyah ${ }^{3}$ \\ Merlitapastore47@gmail.com¹, Siti.rukiyah@rocketmail.com², Arif_acong@yahoo.com³ \\ Universitas PGRI Palembang
}

\begin{abstract}
Abstrak -- Penelitian ini mengkajiragam gaya bahasadan persajakanpada kumpulan lagu Armadi Raga dalam album $A u$.Tujuan dalam penelitian ini untuk mendeskripsikan jenis gaya bahasa dan persajakan pada kumpulan lagu Armadi Raga dalam album $A u$. Metode yang digunakan pada penelitian ini adalah metode deskriptif kualitatif. Teknik pengumpulan data penelitian inimenggunakan teknik cakap (wawancara), simak, dan catat.Berdasarkan hasil analisis yang ditemukan25 gaya bahasadan yang dominan paling seringdigunakanpadakumpulan lagu Armadi Raga adalah gaya bahasa/majastautologi sebanyak 8, hiperbola 5 kali, simile 4 kali, litotes 4 kali, metafora 1 kali, metonimia 1 kali, kontradiksiointerminis 1 kali, dansinisme 1 kali. Selanjutnya pada persajakan ditemukan 16 sajak meliputi sajak akhir 7, sajak awal 6 kali, sajak tengah 2 kali, sajak tak sempurna 1 kali.
\end{abstract}

Kata kunci:Gaya Bahasa, Sajak, Lagu

\section{ANALYSIS OF LANGUAGE AND TAXATION ON ARMADI SONG SONG COLLECTION IN AU ALBUM}

\begin{abstract}
This study discusses the various language styles and poetry in the Armadi Raga song collection on the album Au. The purpose of this study is to describe the types of language and poetry in the Armadi Raga song collection on the Au album. The method used in this research is descriptive qualitative method. This research data collection technique uses the techniques of proficiency (interview), listening, and note taking. Based on the results of the analysis found 25 language styles and the dominant most frequently used in the Armadi Raga song collection is the style of language / majastautology as much as 8 times, hyperbole 5 times, simile 4 times, litotes 4 times, metaphor 1 time, metonymy 1 time, contradictory point 1 time, and cynicism 1 time. Furthermore, in poetry found 16 poems, including rhymes ending 7, rhymes beginning 6 times, rhymes middle 2 times, rhymes imperfect 1 time.
\end{abstract}

Keywords: Language Style, Rhymes, Songs

Artikel Diterima:01-07-2020 Artikel Disetujui:24-02-2021 Artikel Dipublikasi:28-02-2021

Corresponden Author: Merlita Sari E-mail:Merlitapastore47@gmail.com DOI: http://dx.doi.org/10.31851/pembahsi.v11i1.4316

\section{PENDAHULUAN}

Sastra adalah suatu kegiatan kreatif, sebuah karya seni. Sastra juga dianggap sebagai karya seni menarik yang imajinatif, fiktif, dan inovatif (Nuraini \& Arifin, 2020). Untuk membuat sebuah karya sastra diperlukan keterampilan berbahasa. Adanya keterampilan 
berbahasa memudahkan penulis untuk merangkai kosakata menjadi kalimatkalimat yang mengandung nilai estetika tinggi (Kasmarani, 2017), sehingga memiliki daya tarik bagi pembacanya.

Keterampilan dalam berbahasa mengikat juga membutuhkan kosakata yang cukup, kekayaan kosakata seseorang ikut menentukan kualitas keterampilan berbahasa orang tersebut(Sugiantomas et al., 2016). Untuk menghasilkan kalimat yang baik.penguasan kosakata adalah tujuan utama agar menciptakan penulis yang mampu berkreativitas dalam menuangkan ide-ide menarik ke dalam sebuah tulisan yang disebut karya sastra. Bahasa yang digunakan oleh penulis berdasarkan tingkat kreativitas ataupun tingkat imajinasi penulis tentang suatu cara memperindah kata-kata menjadi karya sastra disebut gaya bahasa.

Keraf (1991)“Gaya atau khususnya gaya bahasa dikenal dalam retorika dengan istilah style. Kata style diturunkan dari kata latin stilus, yaitu semacam alat untuk menulis pada lempeng lilin(Heru, 2018). Keahlian menggunakan alat ini akan mempengaruhi jelas tidaknya tulisan pada lempeng tadi."

Berdasarkan uraian di atas, dapat disimpulkan bahwa gaya bahasa adalah suatu cara seseorang untuk mengekspresikan dirinya baik dalam tingkah laku ataupun tulisan yang bertujuan untuk mengekspose dirinya sendiri agar bisa dipahami oleh orang lain.

Dari penjelasan tersebut maka lirik merupakan bentuk sastra yang bukan hanya puisi namun disajikan dengan bentuk nyanyian, lirik termasuk genre sastra imajinatif. Setiap lirik lagu yang telah dibuat pasti memiliki tujuan tertentu. Lagu berisi barisan kata-kata yang dirangkai secara baik dengan gaya bahasa yang menarik oleh pengarang dan dibawakan dengan suara indah penyanyi. Masyarakat dapat menikmati sebuah karya sastra yaitu melalui lagu(Yusnaini, 2020). Lagu tidak hanya hiburan semata, akan tetapi banyak sekali makna yang tersirat dari tiap kata dalam bait lagu, baik dari segi budaya, adat istiadat, nilainilai moral dan bahasa yang digunakan. Di dalam lagu terdapat sajak dan variasi bahasa sehingga lagu tersebut terdengar indah dan memiliki makna tersendiri dihati pendengar.

Keraf (1991) menyatakan Gaya atau khususnya gaya bahasa dikenal dalam retorika dengan istilahstyle. Kata style diturunkan dari bahasa Latin stilus, yaitu semacam alat untuk menulis pada lempengan lilin. Berdasarkan pendapat para ahli di atas, dapat disimpulkan 
bahwa, gaya bahasa adalah sebuah alat untuk menuangkan dan mengekspresikan bahasa kedalam tulisan dengan bahasabahasa yang indah sehingga mempengaruhi pembaca agar tertarik hingga terpukau atas karya yang telah ditulis.

Rais (2012) mengemukakan "secara umum, jenis-jenis majas di bagi menjadi empat bagian yaitu: (1) majas perbandingan, (2) majas pertentangan, (3) majas sindiran, (4)majas penegasan. Berdasarkan uraian di atas, dapat disimpulkan bahwa pengelompokan gaya bahasa bermacam-macam bentuknya (Arisman, 2016). Dalam mengemukakan pendapatnya para ahli memiliki gaya dan pandangannya masing-masing untuk mengembangkan teorinya dengan tujuan yang sama. Untuk mengelompokkan gaya bahasa peneliti menggabungkan dari beberapa pendapat di atas, yang mana sesuai dengan kebutuhan objek peneliti adapun pengelompokan gaya bahasa yang dipilih sesuai kebutuhan objek sebagai berikut.

\section{a. Jenis-Jenis Persajakan atau} Rima

Persajakan atau rima terbagi atas enam bagianyaitu, (sajak awal, sajak tengah, sajak akhir, asonansi, sajak sempurna, sajak tak sempurna)(Indriyana \& Handayaningsih, 2015).Sajak adalah persamaan bunyi. persamaan yang terdapat pada kalimat atau perkataan, di awal, di tengah, dan di akhir perkataan (Waridah, 2013). Sajak terbagi menjadi enam jenis, yaitu sebagai berikut: a. sajak awal, b. Sajak tengah, c. Sajak akhir, d. Sajak asonansi, e. Sajak sempurna, dan f. Sajak tak sempurna.

\section{b. Pengertian Sajak atau Rima}

Sajak mengungkapkan perasaan serta pemikiran penyair secara imaginatif dan disusun dengan menumpukan semua tulisan(Cahyadi \& KOSWARA, 2016). Maksud persajakan adalah bunyi atau permainan bunyi berpola estetika bahasa berupa peulangan dalam bentuk sajak adalah khusus, suara yang diciptakan untuk menimbulkan daya repetisi atau efek keindahan.

\section{METODE PENELITIAN}

Metode penelitian adalah cara yang digunakan peneliti untuk memecahkan masalah dalam penelitian mengenai objek tertentu, dan karenanya harus sesuai dengan kodrat keberadaan objek itu. Metode penelitian berarti cara yang dipergunakan seorang peneliti di dalam usaha memecahkan masalah yang di teliti(Siswantoro, 2010).

\section{HASIL DAN PEMBAHASAN}


Data dalam penelitian ini adalah kumpulan lagu Armadi Raga dalam album $A u$. Album ini dibuat pada tahun 2013 dan diproduksi dan dipasarkan olehEnim Record yang berjumlah delapan belas lagu. Dari delapan belas lagu yang terdapat dalam album tersebut, penulis akan meneliti sebanyak sepuluh lagu saja. Ada pun sepuluh judul lagu yang akan penulis analisis yaitu, 1) au, 2) kulak payu kulu payu, 3) miang hebung, 4) kekibang duson, 5) pangkalan umbak, 6) kakang peluh, 7) cap gerpu, 8) hebung tue, 9) jale kerap, 10) adeng betine.

Dari sepuluh lagu yang akan dianalisis, peneliti menandai setiap bait lagu dengan memberi penomoran pada setiap ujung penggalan syair lagu. Kemudian, peneliti menganalisis lagulagu tersebut berdasarkan jenis gaya bahasa dan persajakannya. Ada pun jenis gaya bahasa yang akan dijadikan acuan penelitian ada empat jenis klasifikasi yaitu, 1) klasifikasi gaya bahasa perbandingan, 2) klasifikasi gaya bahasa penegasan/ perulangan, 3) klasifikasi gaya bahasa pertentangan, dan 4) klasifikasi gaya bahasa pertautan namun pada penelitian ini penulis juga membahas tentang persajakan, klasifikasi jenis persajakan atau rima yang akan dijadikan acuan penelitian ada tiga yaitu, 1) klasifikasi sajak atau rima berdasarkan bunyinya, 2) klasifikasi sajak atau rima berdasarkan letaknya dalam baris, dan 3) klasifikasi sajak atau rima berdasarkan letaknya pada bait.

\section{Deskripsi Data Lagu Armadi Raga "Au" dalam Album Au.}

Au

Au... lemak di dengan au (1)

Nyabun baju nyabun kain (2)

Urungkan ku uleh kain (3)

Dai alap anak jeme gerut pule (4)

Au... dikmak di aku au (5)

Gigit semut gigit sehengge (6)

Bujang karut sare pule (7)

Maaf nian aku telinjang, ngguk dengan au...(8)

Henggi ngginak pacat (9)

Jeme tue dengan (10)

Jauh lebih henggi (11)

Nginak aku ini oy...(12)

Injik tegah simpai (13)

Jeme tue dengan (14)

Timbang tengah aku (15)

Nak jadi menantu (16)

Tupak kuning (17)

Tupak kene la duku (18)

Nindak au nindak nerime aku (19)

Luk ikan seluang (20)

Linjang nyelundang (21) 
Oy kene tube (22)

\section{1) Deskripsi Data Gaya Bahasa} dalam Lagu Armadi Raga "Au”

Syair lagu "Au" dideskripsikan bahwa dalam lagu“Au"ditemukan ada lima jenis gaya bahasa yaitu, a) gaya bahasa hiperbola, b) baya bahasa litotes, c) gaya bahasa sinisme, d) gaya bahasa tautologi, e) gaya bahasa simile.

\section{a) Gaya Bahasa Hiperbola.}

Gaya bahasa hiperbola ditemukan pada penggalan syair lagu "Au" nomor (4)

"Dai alap anak jeme gerut pule" (4)

Penggalan syair lagu "Au" nomor (4) di atas, dijelaskan lagu "Au" menggambarkan seorang pria miskin yang mencintai seorang gadis anak orang kaya berharta yang mana gadis tersebut telah dijodohkan dengan anak orang gedongan. Kata "gerut/gedongan" adalah kata lain dari orang kaya, dalam kata lain penyebutan "anak jeme gerut pule" terlalu berlebih-lebihan padahal bisa dituliskan dengan "anak orang kaya".

\section{b) Gaya Bahasa Litotes.}

Gaya bahasa litotes ditemukan dalam penggalan syair lagu “Au” nomor (7).

1) "Bujang karut sare pule" (7)

Penggalan syair lagu "Au” nomor (7) di atas, menjelaskan sebuah pengakuan seorang laki-laki miskin dengan tujuan merendahkan dirinya sendiri dihadapan orang tua wanita yang dicintainya, maka dari itu kalimat di atas termasuk dalam gaya bahasa litotes.

\section{c) Gaya Bahasa Sinisme.}

Gaya bahasa sinisme ditemukan dalam penggalan syair lagu "Au" nomor (9), (10), (11), (12), (13), (14), (15), dan (16).

1) "Henggi nginak pacat" (9)

2) "Jeme tue dengan" (10)

3) "Jauh lebih henggi” (11)

4) "Nginak aku ini oy ..." (12)

5) "Injik tegah simpai" (13)

6) "Jeme tue dengan" (14)

7) "Timbang tegah aku" (15)

8) “Nak jadi menantu” (16)

Penggalan syair lagu "Au" nomor (9), (10), (11), (12), (13), (14), (15), dan (16) di atas, dalam keseluruhan syair lagu "Au" menggambarkan sindiran atau hinaan kedua orang tua wanita tersebut denganmenyamakan dirinya dengan hewan.

\section{d) Gaya Bahasa Tautologi.}

Gaya bahasa tautologi ditemukan dalam penggalan syair lagu "Au” nomor (19).

1) "Nindak au nindak nerime aku" (19). 
Penggalan syair lagu "Au" nomor (19) di atas, menggunakan perulangan kata "nindak" yang diulang sebanyak dua kali, kata tersebut termasuk gaya bahasa tautologi.

\section{e) Gaya Bahasa Simile.}

Gaya bahasa simile ditemukan dalam penggalan syair lagu "Au" nomor (20), (21), dan (22).

1) “Luk ikan seluang”(20)

2) "Linjang nyeludang" (21)

3) "Oy kene tube" (22)

Penggalan syair lagu "Au" nomor (20), (21), dan (22) di atas, termasukgaya bahasa simile karena kata "luk" yang artinya "seperti". menggambarkan kondisi pria tersebut seperti ikan yang diracun.

\section{2) Deskripsi Data Persajakan dalam}

\section{Lagu Armadi Raga "Au"}

Syair lagu "Au", dapat di deskripsikan bahwa dalam lagu "Au" di temukan dua jenis sajak atau rima yaitu, a) sajak atau rima akhir, 2) sajak atau rima awal.

\section{a) Sajak atau Rima Akhir}

Sajak atau rima akhir ditemukan dalam penggalan syair lagu "Au" nomor (2), dan (3).

1) "nyabun baju nyabun kain" (2)

2) "urungan ku uleh lain" (3)

Penggalan syair lagu "Au" nomor (2), dan (3) di atas, terdapat kata akhiran "kain" dan "lain" yang mana kedua kata tersebut sama-sama memiliki akhiran suku kata "in" membuktikan bait syair lagu "Au" menggunakan sajak akhir.(bait ke-1)

\section{b) Sajak atau Rima Awal}

Sajak atau rima awal ditemukan dalam penggalan syair lagu "Au" nomor (17), dan (18).

1) “Tupak kuning" (17)

2) “Tupak kane lah duku” (18) (bait ke-5)

Penggalan syair lagu "Au" nomor (17), dan (18) di atas, sama-sama di awali oleh kata yang sama yaitu, kata "tupak". Karena persamaan kata dan letaknya terdapat diawal pada tiap bait, maka penggalan syair lagu di atas disebut dengan sajak atau rima awal.

Gaya Bahasa pada Kumpulan Lagu Armadi Raga dalam Album "Au”

Berdasarkan hasil analisis data pada bagian sebelumnya, dapat diketahui bahwa pada kumpulan lagu Armadi Raga dalam album "Au" berjumlah 18 lagu. Dari 18 lagu yang terdapat dalam album tersebut, penulis hanya meneliti 10 lagu saja. Pemilihan lagu tersebut didasari oleh beberapa alasan 1) berdasarkan kajian awal, ditemukan gaya bahasa dan persajakan pada 10 lagu tersebut, 2) lagulagu tersebut menggunakan bahasa 
daerah yang merupakan bahasa bagian dari bahasa Indonesia secara utuh, 3) sepuluh lagu tersebut paling sering didengar masyarakat baik diputar diradio lokak ataupun DVD/VCD selanjutnya pada kumpulan lagu Armadi Raga terutama dalam 10 lagu tersebut mempunyai keterkaitan unsur bahasa dan sastra terlihat dari hasil analisis yang telah dilakukan penulis.

Keterkaitan tersebut meliputi adanya gaya bahasa sebagai konteks sastra yang melekat pada objek kumpulan lagu Armadi Raga yang hakikatnya merupakan konteks bahasa. hal tersebut dibuktikan dengan ditemukannya empat jenis klasifikasi gaya bahasa yang meliputi: klasifikasi gaya bahasa perbandingan, klasifikasi gaya bahasa pengulangan/penegasan, klasifikasi gaya bahasa pertentangan, dan klasifikasi gaya bahasa pertautan.

Statistik data kumpulan lagu Armadi Raga dalam album "Au" menyatakan bahwa gaya bahasaperbandingan menduduki jumlah terbanyak yang digunakan pada kumpulan lagu Armadi Raga dalam album "Au" dengan total 15 kali, yang meliputi, gaya bahasa hiperbola (5 kali), gaya bahasa litotes (4 kali), gaya bahasa simile (4 kali), gaya bahasa metafora (1 kali), dan gaya bahasa metonimia (1 kali). Gaya bahasa perbandingan adalah kata kiasan yang memunculkan perbandingan untuk memberikan kesan atau pengaruh tertentu bagi orang yang membaca maupun orang yang mendengarnya. Salah satu ciri gaya bahasa perbandingan ini adalah adanya hal yang diperbandingkan baik secara langsung maupun secara tidak langsung. Keterkaitan gaya bahasa hiperbola tersebut terdapat pada konteks bahasa dan pemaknaan hiperbola yang memiliki makna berlebih-lebihan yang terlahir dari teks syair-syair lagu tersebut.

Pada kumpulan lagu Armadi Raga dalam album "Au" juga menyatakan bahwa gaya bahasa hiperbola merupakan jenis gaya bahasa yang dominan muncul dalam kumpulan lagu Armadi Raga dalam album "Au". Gaya bahasa hiperbola merupakan salah satu jenis klasifikasi gaya bahasa perbandingan yang mengungkapkan sesuatu dengan cara dilebih-lebihkan. Penggunaan kata yang memiliki makna yang berlebihlebihan sering muncul pada kumpulan lagu Armadi Raga dalam album "Au".

Persajakan pada Kumpulan Lagu Armadi Raga dalam Album "Au"

Berdasarkan hasil analisis data pada bagian sebelumnya, dapat di ketahuai bahwa pada kumpulan lagu Armadi Raga 
mempunyai keterkaitan unsur bahasa dan sastra. Keterkaitan tersebut meliputi adanya sajak sebagai konteks sastra yang melekat pada kumpulan lagu Armadi Raga yang hakikatnya merupakan konteks bahasa. Hal tersebut dibuktikan dengan ditemukan sajak atau rima pada kumpulan lagu Armadi Raga dalam album "Au" . statistik data menyatakan sajak yang banyak dipergunakan dalam kumpulan lagu Armadi Raga dalam album "Au" adalah sajak atau rima akhir menduduki jumlah terbanyak dengan total 7 kali. Untuk lebih jelas pengklasifikasian sajak sebagai berikut: sajak atau rima akhir (7 kali), sajak atau rima awal (6 kali), sajak atau rima tengah (2 kali), dan sajak atau rima asonansi (1 kali). Klasifikasi jenis sajak ini membicarakan mengenai pengulangan bunyi yang dihimpun dari pola suku kata atau kata akhir pada tiap kalimat yang tersusun dari atas ke bahwa (vertikal). Hal tersebut, membuktikan bahwa pola kesusastraan dengan menghadirkan sederetan pengulangan bunyi yang menghasilkan suatu estestika yang menarik.

Pada kumpulan lagu Armadi Raga dalam album "Au" juga menyatakan bahwa sajak atau rima yang dominan muncul pada kumpulan lagu Armadi Raga dalam album "Au" adalah sajak atau rima akhir. Sajak atau rima akhir merupakan persamaan bunyi huruf hidup (vokal) yang terdapat dalam perkataan atau kalimat yang letaknya di akhir kalimat.

\section{KESIMPULAN}

Hasil penelitian dan pembahasan yang telah penulis lakukan, diperoleh simpualn bahwa pada kumpulan lagu Armadi Raga dalam album "Au" terdapat 8 jenis gaya bahasa yang meliputi: perbandingan, pertentangan, sindiran dan perulangan/penegasan. yaitu gaya bahasa tautologi sebanyak 8 kali, gaya bahasa hiperbola 5 kali, gaya bahasa simile 4 kali, gaya bahasa litotes 4 kali, gaya bahasa metafora 1 kali, gaya bahasa metonimia 1 kali, gaya bahasa kontradiksio interminis 1 kali, gaya bahasa sinisme1 kali. Dari ke empat klasifikasi jenis gaya bahasa tersebut yang dominan muncul adalah gaya bahasa perulangan/penegasan, pada jenis gaya bahasa tautologi. Pada penelitian ini peneliti juga membahas tentang persajakan pada kumpulan lagu Armadi Raga dalam album "Au" yang meliputi, sajak atau rima awal sebanyak 6 kali, sajak atau rima akhir sebanyak 7 kali, sajak atau rima tengah sebanyak 2 kali, dan sajak atau rima tak sempurna sebanyak 1 kali. Sajak atau rima yang 
sering muncul pada kumpulan lagu Armadi Raga adalah sajak atau rima akhir. Sajak atau rima akhir adalah sajak yang terjadi perulangan/ persamaan bunyi pada akhir kalimat.

\section{DAFTAR PUSTAKA}

Arisman, M. (2016). Analisis majas dalam novel ayah karya andrea hirata dan rencana pelaksanaan pembelajarannya di kelas xi sma [phd thesis]. Pbsi-fkip.

Cahyadi, A. D., \& Koswara, D. (2016). Kajian struktural, stilistika, dan etnopedagogi dalam kumpulan puisi (sajak) periode tahun 2000an. Lokabasa, 5(1).

Heru, A. (2018). Gaya bahasa sindiran ironi, sinisme dan sarkasme dalam berita utama harian kompas. Jurnal pembahsi (pembelajaran bahasa dan sastra indonesia), $8(2), 43$.

Indriyana, H., \& Handayaningsih, S. (2015). Pintar bahasa indonesia super lengkap. Indonesiatera.

Kasmarani, M. (2017). Analisis stilistika novel daun yang jatuh tak pernah membenci angin karya tere liye dan novel belenggu merah muda karya tyas damaria. Jurnal pembahsi (pembelajaran bahasa dan sastra indonesia), 7(2), 19.
Keraf, G. (1991). Narasi dan argumentasi. Jakarta: gramedia.

Nuraini, A., \& arifin, E. Z. (2020). Nilai kehidupan dan moral dalam novel ranah 3 warna karya ahmad fuadi. Diskursus: jurnal pendidikan bahasa indonesia, 3(01), 1-8.

Rais, P. (2012). Panduan super lengkap majas eyd peribahasa. Yogyakarta: buku pintar.

Siswantoro. (2010). Metode penelitian sastra.

Sugiantomas, A., Jaelani, A. J., \& Maesaroh, E. (2016). Perbandingan sk dan kd pada standar isi kurikulum 2006 dengan ki dan kd pada standar isi kurikulum 2013 mata pelajaran bahasa indonesia smp kelas vii dilihat dari taksonomi tujuan pembelajaran, cakupan ilmu keterampilan berbahasa, ilmu kebahasaan, dan ilmu kesastraan. Fon: jurnal pendidikan bahasa dan sastra indonesia, 9(2).

Waridah, E. (2013). Eyd; ejaan yang disempurnakan \& seputar kebahasa-indonesiaan. Ruang kata.

Yusnaini, Y. (2020). Makna simbolik dan kritik sosial dalam kumpulan puisi doa untuk anak cucu karya ws. Rendra. Jurnal pembahsi (pembelajaran bahasa dan sastra indonesia), 10(1), 48-66. 